Дитяча стоматологія

УДК 616-01/-099:31

DOI 10.11603/2311-9624.2017.4.8218

(C). Ю. Гончарук-Хомин

ДВН3 «Ужгородський національний університет»

\title{
Огляд ефективності використання судово-стоматологічних методів визначення віку дітей та підлітків
}

Резюме. Значна кількість методів визначення віку дітей та підлітків за стоматологічним статусом, наявних на сьогодні, не сприяє вирішенню ключової проблеми - забезпечити повну відповідність між даними, отриманими в ході обрахунку дентального віку, та дійсним хронологічним віком особи. Мета дослідження - провести комперативний аналіз ефективності використання методів визначення віку дітей та підлітків за даними одонтологічного статусу з виокремленням найбільш точних підходів, що можуть бути імплементовані в ході судово-медичних та судово-стоматологічних досліджень.

Матеріали і методи. Для проведення пошуку публікацій використовували форму запиту Google Aкадемії (http://scholar.google.com) щодо застосування функції розширеного пошуку. В ході пошуку застосовували такі специфічні види операторів, як «+»- 3 метою надання загальних вказаних назв теми пошуку («dental age», «children», «adolescents»), «пошук за фразою» («forensic age estimation among children», «forensic age estimation among adolescents») та «в заголовку» («dental age» та «children», «dental age» та «adolescents», «forensic age estimation» та «children», «forensic age estimation» та «adolescents»).

Результати досліджень та їх обговорення. Резюмуючи результати аналізу вивченої літератури, можна дійти до висновку, що на сучасному етапі має місце недостатній рівень систематизації існуючих методів визначення віку особи за стоматологічним статусом та методів оцінки достовірності отриманих результатів у різних вікових групах при імплементації різних методологічних підходів. Тому апробація найбільш точних, за даними ретроспективного огляду літератури, методів верифікація дентального віку, а саме Demirjian, Haavikko, Cameriere, Willems та розробка відповідного алгоритму рекомендацій щодо комбінованого їх використання чи модифікації окремих етапів обрахунку та інтерпретації даних є релевантним науково-практичним завданням, що потребує актуального вирішення.

Висновки. Проведення відповідних теоретичних та практичних досліджень із достатньою кількістю вихідного матеріалу дозволить обгрунтувати специфічні критерії оцінки результатів визначення віку за стоматологічним статусом у різних вікових групах при різних методологічних підходах, що, у свою чергу, дозволить спростити алгоритм судово-стоматологічної оцінки зубощелепного апарату в ході проведення комплексних судово-медичних експертних та слідчих заходів. На даний момент в якості найбільш точних методик для визначення віку дітей та підлітків, за даними стоматологічного статусу, можуть бути виокремлені підходи Demirjian, Haavikko, Cameriere, Willems.

Ключові слова: дентальний статус; судова стоматологія; одонтологічні критерії.

(С). Ю. Гончарук-Хомин

ГВУЗ «Ужгородский национальный университет»

\section{Обзор эффективности использования судебно-стоматологических методов определения возраста детей и подростков}

Резюме. Значительное количество методов определения возраста детей и подростков по стоматологическому статусу, имеющихся на сегодня, не способствует решению ключевой проблемы - обеспечить полное соответствие между данными, полученными в ходе расчета дентального возраста и действительным хронологическим возрастом человека.

Цель исследования - провести комперативний анализ эффективности использования методов определения возраста детей и подростков по данным одонтологического статуса с выделением наиболее точных подходов, которые могут быть реализованы в ходе судебно-медицинских и судебно-стоматологических исследований.

Материалы и методы. Для проведения поиска публикаций использовалась форма запроса Google Академии (http://scholar.google.com) с применением функции расширенного поиска. В ходе поиска применяли такие специфические виды операторов, как «+»- с целью предоставления общих указанных названий темы поиска («dental age», «children», «adolescents»), «поиск по фразе» («forensic 
age estimation among children», «forensic age estimation among adolescents») и «в заголовке» ( «dental age» и «children», «dental age» и «adolescents», «forensic age estimation» и «children», «forensic age estimation» и «adolescents»).

Результаты исследований и их обсуждение. Резюмируя результаты анализа изученной литературы, можно прийти к выводу, что на современном этапе имеет место недостаточный уровень систематизации существующих методов определения возраста человека по стоматологическому статусу и методов оценки достоверности полученных результатов в различных возрастных группах при имплементации различных методологических подходов. Поэтому апробация наиболее точних, по данным ретроспективного обзора литературы, методов верификация дентального возраста, а именно Demirjian, Haavikko, Cameriere, Willems и разработка соответствующего алгоритма рекомендаций для комбинированного их использования или модификации отдельных этапов расчета и интерпретации данных является релевантной научно-практической задачей, требующей актуального решения. Выводы. Проведение соответствующих теоретических и практических исследований с достаточным количеством исходного материала позволит обосновать специфические критерии оценки результатов определения возраста по стоматологическому статусу в разных возрастных группах при различных методологических подходах, что, в свою очередь, позволит упростить алгоритм судебностоматологической оценки зубочелюстного аппарата в ходе проведения комплексных судебно-медицинских экспертных и следственных мероприятий. На данный момент в качестве наиболее точных методик для определения возраста детей и подростков, по данным стоматологического статуса, могут быть выделены подходы Demirjian, Haavikko, Cameriere, Willems.

Ключевые слова: дентальный статус; судебная стоматология; одонтологические критерии.

\section{Yu. Honcharuk-Khomyn}

Uzhhorod National University

\section{Review of the forensic dental methods efficiency for age estimation of children and adolescents}

Summary. A significant number of currently available methods for dental age estimation among children and adolescents does not actually contribute for solving a key problem, which based on ensuring full correspondence between the data obtained during the calculation of the dental age and the actual chronological age of the person.

The aim of the study - to conduct a comparative analysis of the effectiveness of different dental age estimation methods among children and adolescents with a selection of the most accurate approaches that can be implemented during forensic and forensic dental research.

Materials and Methods. The Google Scholar Request Form (http://scholar.google.com) was used to search publication on relevant toping with additional using of the Advanced Search option. During the search, such specific types of operators as «+» were used to provide general named titles of the search («dental age», «children», «adolescents»), "search by the phrase» («forensic age estimation among children», "forensic age estimation among adolescents») and «in title» ( «dental age» and «children», "dental age» and «adolescents», «forensic age estimation" and «children», «forensic age estimation» and "adolescents»).

Results and Discussion. Summing up the results of the analysis of the studied literature, we can conclude that at the present stage there is an insufficient level of systematization of existing methods for dental age estimation and methods for assessing the reliability of the results obtained in different age groups during the implementation of various methodological approaches. Therefore, testing the most accurate methods, obtained from the retrospective review of the literature, such as methods of Demirjian, Haavikko, Cameriere, Willems, and the development of a suitable algorithm for the recommendations for their combined use or modification of certain stages during calculation and interpretation of data is relevant scientific and practical task that require actual solution.

Conclusions. Conduction of further appropriate theoretical and practical studies with sufficient amount of source material will allow to substantiate specific criteria for assessing the results of age estimation by dental status in different age groups with different methodological approaches, which in turn will simplify the forensic evaluation of the dento-facial system during the implementation of complex forensic examinations and investigations. Currently Demirjian, Haavikko, Cameriere, and Willems approaches can be identified as the most accurate methods for determining the age of children and adolescents according to odontological data.

Key words: dental status; forensic dentistry; odontological criteria. 
Вступ. Ідентифікація особи, за стоматологічним статусом, передбачає можливості для проведення порівняльних процедур (зіставлення наявних стоматологічних доведень чи ознак із такими, що можуть бути верифіковані в процесі деталізованого дослідження), реконструктивних маніпуляцій (формування профілю особи за стоматологічними ознаками - визначення статі, віку, етнічних особливостей, виду практичної діяльності, причин та часу смерті), та ДНК-профайлінгу, як найбільш достовірного методу встановлення особи за генетичним матеріалом, узятим із ротової порожнини [1]. Вищеперелічені заходи часто використовують у ході ідентифікації жертв масових катастроф, коли сам процес встановлення осіб загиблих носить строго організований характер, та розгортається на базі мобільних судово-медичних центрів із залученням спеціалістів різних галузей та дотриманням протоку DVI/Interpol [2-4]. До критеріїв, визначення яких у ході масового дізнання чи окремих судово-медичних експертиз є обов'язковими, відносять стать, вік та етнічну приналежність особи, що дозволяють значно зменшити первинну вибірку порівняння та оптимізувати процес ідентифікації [5]. Проте якщо окремі антропологічні ознаки скелета дозволяють із достеменною точністю верифікувати ключові моменти гендерного диморфізму чи окремої популяційної групи, то аспект уніфікованого підходу до визначення віку досі залишається відкритим питанням судово-медичної науки та практики. 3 іншого боку, вік є єдиним чисельним показником, точна верифікація якого можлива навіть в умовах скелетизації тіл, чи при фрагментації трупних залишків, оскільки ознаки старіння організму чітко асоційовані з особливостями формування та розвитку окремих анатомічних ділянок, у тому числі й зубощелепного апарату [6-8]. Значна кількість наявних на сьогодні методів визначення віку дітей та підлітків за стоматологічним статусом не сприяє вирішенню ключової проблеми - забезпечити повну відповідність між даними, отриманими в ході обрахунку дентального віку, та дійсним хронологічним віком особи. Таким чином, для виокремлення найбільш точних методик, обгрунтованим $є$ проведення ретроспективного аналізу ефективності використання різних методів визначення віку за стоматологічним статусом, які використовують у практиці європейських судово-медичних досліджень.
Метою дослідження було провести комперативний аналіз ефективності використання методів визначення віку дітей та підлітків за даними одонтологічного статусу з виокремленням найбільш точних підходів, що можуть бути імплементовані в ході судово-медичних та судово-стоматологічних досліджень.

Матеріали і методи. Для проведення пошуку використовували форму запиту Google Академіï(http://scholar.google.com) із застосуванням функції розширеного пошуку. В ході пошуку застосовували такі специфічні види операторів, як «+» - 3 метою надання загальних вказаних назв теми пошуку («dental age», «children», «adolescents»), «пошук за фразою» («forensic age estimation among children", «forensic age estimation among adolescents») та «в заголовку» ( dental age» та «children», «dental age» та «adolescents», «forensic age estimation» та «children», «forensic age estimation» та «adolescents»). Вищезгаданий алгоритм пошуку дозволив автоматично систематизувати стать осіб та категоризувати їх за конкретною тематикою щодо практики використання різних методів визначення віку дітей та підлітків за стоматологічним статусом, забезпечивши також поступове сортування результатів пошуку з формуванням групи вибірки публікацій, які найбільше відповідали поставленій меті дослідження. При цьому кожний результат являв собою групу окремо відібраних публікацій, що підлягали подальшому контент-аналізу. Групування чисельних показників ефективності використання різних підходів до верифікації дентального віку серед вищезгаданої вікової групи проводили у табличному редакторі Microsoft Excel (Microsoft Office, 2013). Вищеописаний підхід дозволяє оптимізувати процес формулювання висновків при реферуванні великих масивів документів, та забезпечує визначення взаємопов'язаних груп дослідження, спрощення процесу перегляду при пошуку необхідної інформації, знаходження унікальних документів із колекції, виявлення аналогічних чи дуже близьких за змістом результатів.

Результати досліджень та ї обговорення. В ході тривалих судово-стоматологічних досліджень було розроблено специфічні рекомендації відносно того, який із наявних на сьогодні методів чи підходів визначення дентального віку $€$ найбільш адаптований до відповідних умов судово-медичного дослідження. Так, у ранньому віці автори радять використовувати методи оцінки розвитку зу- 
бощелепного віку, цінність яких зменшується із завершенням стадії формування організму дитини [9, 10]. Найбільш пізнішою модифікацією даних підходів є верифікація дентального віку за ознаками розвитку третього моляра в осіб вікового діапазону 18-21 рік. У дорослому віці достовірність морфологічних методів значно зменшується, однак рекомендованим $€$ використання біохімічних підходів до визначення віку осіб за стоматологічним статусом.

Окремі судово-стоматологічні підходи пропонують схематичну оцінку градації ступеня розвитку стоматологічного статусу, що дозволяє ідентифікувати осіб у діапазоні від 5 місяців внутрішньоутробного розвитку до 35 років, при цьому рівень абсолютної похибки коливається в межах \pm 2 місяців-3 років [11, 12]. Проблема полягає лише в тому, що орієнтовно у 14-15 років, залежно від популяційних та етнічних особливостей, більшість одиниць зубного ряду завершує своє формування, і єдиним елементом, доступним для дослідження та значущим для отримання достовірного результату, залишається третій моляр. Хоча за результатами окремих досліджень, варіативність стадій розвитку та можливість уродженої відсутності даної зубної структури значно зменшує ідентифікаційну значимість третього моляра як ідентифікаційного критерію для верифікації показників дентального віку.

P. Thevissen та колеги (2012) відмітили, що використання показників розвитку третього моляра як надійного критерію оцінки дентального віку, є достатньо дискусійним, враховуючи асиметричність розвитку та становлення даного зуба на верхній та нижній щелепах, у межах однієї щелепи 3 різних боків та індивідуальну й етнічну варіативність даних процесів [10]. 3а даними загальнопопуляційних спостережень, на початкових стадіях формування зуба різниця між дійсними та обрахованими віковими показниками може сягати до 2 років, з обов'язковим урахуванням того факту, що розвиток конкретно даних зубів у чоловіків відбувається швидше, ніж у жінок. Крім того, враховуючи статистично доведені відхилення результатів обчислення дентального віку в діапазоні 8-16 років, що можуть сягати 1,5-2,6 року, дослідники запропонували критерій ідентифікації віку особи за критерієм «понад 20 років» за умов, що ступінь розвитку третього моляра, що показано на прицільній рентгенограмі, відповідає останній стадії його формування, запропонованій у модифікованому підході за Demirjian.
D. Franklin (2015) запропонував оригінальний метод верифікації віку осіб до 18 років шляхом аналізу мультиваріативних тривимірних дескрипторів розміру нижньої щелепи, при цьому рівень девіацій при використанні даної методики не перевищує $\pm 1,3-3,0$ років [13].

V. M. Phillips та van Wyk T. J. Kotze (2009) довели важливість особливостей проживання та способу життя на результати визначення віку за стоматологічним статусом [14]. При апробації методу Moorrees-Fanning-Hunt на групі південноафриканських дітей було виявлено, що отримані результати менші за об'єктивні показники віку, при чому така ситуація спостерігалась у $90 \%$ усіх осіб трьох досліджуваних груп. У свою чергу, метод за Demirjian-Goldstein-Tanner провокував завищення показників дентального віку відносно реальних хронологічних параметрів дітей у трьох досліджуваних групах (у 79,2 \%; 86,3 та 90 \% дітей у кожній групі дослідження відповідно).

У ході перевірки методу G. Demirjian Willems та колеги також виявили, що даний підхід провокує завищення вікових показників у бельгійських дітей у середньому на 0,5-1 рік, при цьому найбільш значущі відхилення було відмічено у хлопчиків 9-10-річного віку та дівчат 9-11 років. Статистично значущі відхилення вікових показників було зареєстровано у кожному з класів верифікації розвитку та становлення зубних одиниць, що свідчить про те, що даний оригінальний підхід провокує виникнення стандартних похибок навіть за умов коректного виконання усіх етапів антропологічного дослідження [15].

H. Liversidge та колеги (2010) також звернули увагу на те, що різні технології визначення дентального віку, навіть за умов проведення експериментального дослідження в межах однієї популяції, характеризуються певними девіаціями: так, методи Willems та Demirjian провокують несуттєву недооцінку показників віку $(-0,05 \pm 0,81$ та $0,25 \pm 0,84-$ у хлопчиків та $-0,20 \pm 0,89$ і 0,23 $\pm 0,84$ - в дівчаток відповідно), разом з тим, як методи Nolla та Haavikko's, навпаки, показують статистично значимі відхилення вікових параметрів $(-0,87 \pm 0,87$ та $-0,56 \pm 0,91-$ у хлопчиків та $-1,18 \pm 0,96$ і $-0,79 \pm 1,11$ - у дівчаток відповідно). Крім того, у дослідженні вдалось встановити, що використання першого та другого премолярів в якості предикторів верифікації вікових даних при 
реалізації підходу Haavikko забезпечує найбільш точні результати визначення вікових параметрів, що підтверджено статистичною значимістю отриманих даних у межах високих довірчих інтервалів [16].

R. Cameriere (2012) запропонував унікальний підхід визначення дентального віку на основі реєстрації ступеня розвитку коренів зубів з обрахунком відстаней між відкритими їх верхівками та внесенням відповідних даних у регресійне рівняння, що має такий вигляд: вік $=8,971+0,375 \mathrm{~g}+1,631 \mathrm{x}_{5}+0,674 \mathrm{No}-1,034 \mathrm{~s}-0,176 \mathrm{sxNo}$,

де $\mathrm{g}$ - коефіцієнт гендеру (1 - для чоловіків, 0 - для жінок), s - сума відкритих верхівок коренів, No - сума зубів із завершеним формування коренів (верхівка закрита), $\mathrm{x}_{5}$ - параметри п’ятого зуба (другого премоляра), який володіє найбільшим рівнем кореляції із показником хронологічного віку. Доведений рівень абсолютної похибки віку в ході обчислення за запропонованою схемою не перевищував 1 року (0,93 року), таким чином, підхід Cameriere є одним із найбільш точних для верифікації вікового показника у діапазоні 5-15 років, що було доказово доведено в ході проведення низки досліджень [17]. Однак відкритим залишається питання можливості адаптації даної методики для інших вікових груп з урахування обмеження факту закриття майже усіх верхівок коренів зубів до 15 років.

S. Flood та колеги (2013), вивчаючи можливість використання методу Demirjian серед дітей західної Австралії, підтвердили відповідну достовірність отриманих результатів та встановили вищу кореляцію отриманих даних із реальними показниками у жіночій вибірці порівняно з чоловічою [18]. Крім того, дослідникам вдалось підтвердити значимість цифрових ортопантомограм в якості первинного матеріалу дослідження, які в подальшому можуть бути адаптовані до особливостей методології запропонованого судово-стоматологічного підходу. Хоча недоліком методу залишається можливість використання зображення лише останніх молярів у якості єдиного ідентифікаційного критерію при досягненні відповідного віку особи, що характеризується завершенням формування зубощелепного апарату. Специфіка використання ортопантомограм у таких ситуаціях полягає саме у можливостях точної реєстрації відповідних показників у ділянці зубів нижньої щелепи, що забезпечують кращу достовірність кінцевих результатів порівняно 3 аналізом відповід- них даних серед зубів верхньої щелепи. Згідно з результатами проведеного статистичного аналізу вдалось встановити, що відсоток вірогідності того, що метод Demirjian забезпечує достатньо чітку відповідність обрахованого дентального віку показнику хронологічного віку серед жіночої вибірки, становить 51,7 \%, разом $з$ тим, як серед вибірки чоловічої статі $-56,4 \%$.

M. Altunsoy та колеги (2012), провівши аналіз можливості адаптації техніки визначення віку за Demirjian на вибірці дітей із північного регіону Туреччини встановив, що середня різниця між хронологічним віком та дентальним віком серед хлопчиків становила 0,36-1,43 року, а серед дівчат - 0,5-1,44 і найбільші девіації даних показників були у віковому діапазоні 5-6,9 року [19]. Виходячи з отриманих результатів, автор зробив висновок, що існує значима різниця у строках формування зубощелепного апарату в дітей французько-канадійської вибірки, що обрано Demirjian в ході початкової розробки методики, та досліджуваної вибірки дітей із регіону північної Туреччини, однак для використання даної методики необхідно провести відповідну корекцію алгоритму верифікації віку з адаптацією відповідних критеріїв до особливостей розвитку організму специфічної етнічної групи населення.

A. Cruz-Landeira (2010) підтвердила існуючу різницю між результатами, отриманими в ході використання методики Demirjian у різних груп населення, на прикладі групи вибірки дітей із Венесуели [20]. Навіть після адаптація полімональних функцій результати верифікації вікових показників у дітей, старше 12 років, демонстрували значні девіації у бік переоцінення дійсних параметрів, 3 метою усунення яких автори запропонували використовувати модифікований підхід Chaillet (2005), що забезпечує отримання достовірних результатів у віковому діапазоні об'єктів дослідження до 14 років.

B. Rai та J. Kaur (2012) проводили оцінку точності використання 4 різних методик визначення дентального віку, а саме, за Demirjian, Willems, Nolla, Haavikko та Cameriere. Найдостовірнішим, згідно з результатами дослідження, виявився метод Willems, точність якого обгрунтована значенням похибки в 0,25 року для хлопчиків і 0,24 року - для дівчаток, при цьому в усіх випадках була переоцінка віку за даною методикою. Усі інші методи, навпаки, демонструють вікові показники, дещо 
менші від дійсних: Haavikko - 0,13 для хлопчиків та 0,12 для дівчаток, Cameriere - 0,20 для хлопчиків та 0,18 для дівчаток, Nolla - 0,29 для хлопчиків та 0,27 для дівчаток, Demirjian - 0,18 для хлопчиків та 0,15 для дівчаток.

M. Blenkin та W. Evans (2010) навпаки стверджують, що метод визначення дентального віку за Demirjian провокує переоцінку реальних вікових параметрів особи. В ході аналізу достовірності та адаптованості методики для населення Сіднея автори розробили модифікацію методу, запропонувавши використання спрощеного критерію формування зубів (Simple Maturity Score - SMS), що являє собою суму відповідних градацій дозрівання зубів за Demirjian від А до Н [22]. На основі проведеного регресійного аналізу в групі вибірки із 2587 цифрових ортопантомограм M. Blenkin та W. Evans розробили спрощені поліноміальні рівняння для достовірної верифікації віку серед населення Сіднея з врахуванням впливу фактора гендерної різниці:

$\mathrm{y}=-2,042579201+0,416441557 \mathrm{x}-0,009307$ $122 \mathrm{x}^{2}+0,000128194 \mathrm{x}^{3}$ - для чоловіків та

$\mathrm{y}=-1,914675804+0,421823224 \mathrm{x}-0,010273636$ $\mathrm{x}^{2}+$ 0,000 $141442 \mathrm{x}^{3}$ - для жінок, де $\mathrm{x} \in$ спрощеним сумарним параметром формування зубів (SMS) [22].

Вплив гетерогенності суспільства на результати визначення дентального віку були підтверджені в дослідженнях Z. Kırzıoğlu та D. Ceyhan (2012), які апробували методи Nolla, Haavikko та Demirjian на вибірці із 425 соматично здорових турецьких дітей віком від 7 до 13 років. У даному дослідженні було встановлено, що метод Haavikko $є$ набільш точним для даної популяційної групи, хоча в цілому він забезпечує отримання показників дещо нижчих від реальних: серед хлопців $-0,60 \pm 0,80$, серед дівчат $-0,56 \pm 0,81$, в обох групах $-0,58 \pm 0,80$. Метод Nolla також дещо занижує дентальний вік досліджуваних осіб відносно об'єктивного хронологічного (серед хлопців $-0,53 \pm 0,95$, серед

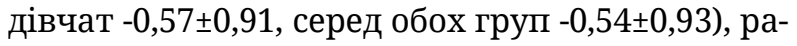
зом $з$ тим, метод Demirjian, навпаки, завищує отримані дані: серед хлопчиків $-0,52 \pm 0,86$, серед дівчат $-0,75 \pm 0,90$, серед обох груп $-0,64 \pm 0,89$ [23].

У ході постійного удосконалення підходів до визначення віку особи за стоматологічним статусом низку досліджень було присвячено питанню систематизації статистичних відхилень при використанні тих чи інших судово-стоматологічних методів. Дослідження, проведені R. Cameriere (2012), встановили, що запропонований авторський метод визначення віку більшості імплементованих випадків провокує незначну недооцінку дентального віку порівняно $з$ дійсним хронологічним показником: у хлопців медіана даної резидуальної різниці сягає 0,081 року, а в дівчат - 0,036 року, при цьому в 38,4 \% випадків різниця між хронологічним та дентальним віком фактично не перевищувала 0,5 року, а в 13,11 \% - 1 року [17]. При використанні методик Willems та Demirjian майже у всіх випадків була переоцінка дійсних вікових показників із середнім рівнем резидуальної різниці у 0,247 та 0,6110,750 року відповідно. Проте абсолютну переоцінку віку за 0,5 року при використанні технік за Willems та Demirjian було відмічено у більшої кількості досліджуваних випадків - 66,8 та 70,9 \% відповідно. Крім того, прогностична помилка методу Cameriere є значно нижчою, ніж методів Willems та Demirjian, і сягає 0,407 для дівчаток і 0,380 року - для хлопчиків. Недолік техніки Cameriere полягає в тому, що достовірність даного методу поступово зменшується 3 віком при наближенні до 15 років, що пов’язано із методологією виконання техніки, та майже повним завершенням формування коренів усіх зубів. Разом з тим, зважаючи на свою простоту та оптимізацію процесу виконання, судово-стоматологічні методи верифікації вікових параметрів осіб за Willems та Demirjian залишаються одними з найпоширенішими в судово-медичній практиці.

Висновки. Резюмуючи результати аналізу вивченої літератури, можна зробити висновок, що на сучасному етапі має місце недостатній рівень систематизації існуючих методів визначення віку особи за стоматологічним статусом та методів оцінки достовірності отриманих результатів у різних вікових групах при імплементації різних методологічних підходів. Тому апробація найбільш точних за даними ретроспективного огляду літератури методів верифікації дентального віку, а саме, Demirjian, Haavikko, Cameriere, Willems, та розробка відповідного алгоритму рекомендацій щодо комбінованого їх використання чи модифікації окремих етапів обрахунку та інтерпретації даних є релевантним науково-практичним завданням, що потребує актуального вирішення. Крім того, дискусійним залишається аспект вибору самого підходу оцінки морфологічних параметрів зубощелепного апарату з метою визначення віку особи та доцільності використання рентгенологічного 
методу діагностики в окремих клінічних випадках.

Перспективи подальших досліджень. Проведення відповідних теоретичних та практичних досліджень із достатньою кількістю вихідного матеріалу дозволить обгрунтувати специфічні критерії оцінки результатів ви-

\section{Список літератури}

1. Feasibility and validation of virtual autopsy for dental identification using the Interpol dental codes / A. Franco, P. Thevissen, W. Coudyzer [et al.] // Journal of Forensic and Legal Medicine. - 2013. - No. 20 (4). - P. 248-254.

2. Lin P. L. Dental biometrics: Human identification based on teeth and dental works in bitewing radiographs P. L. Lin, Y. H. Lai, P. W. Huang // Pattern Recognition. 2012. - No. 45 (3). - P. 934-946.

3. Berketa J. W. Forensic odontology involvement in disaster victim identification / J. W. Berketa, H. James, A. W. Lake // Forensic Science, Medicine, and Pathology. - 2012. - No. 8 (2). - P. 148-156.

4. Forensic odontology in the disaster victim identification process / P. Pittayapat, R. Jacobs, E. De Valck [et al.] // J. Forensic Odontostomatol. - 2012. No. 30 (1). - P. 1-12.

5. Dental and oral features useful in identification / C. Stavrianos, E. Georgaka, G. Sarafidis [et al.] // Research Journal of Medical Sciences. - 2012. - No. 6 (2). - P. 33-41. 6. Age estimation for forensic purposes in Italy: ethical issues / M. Focardi, V. Pinchi, F. De Luca, G. A. Norelli // International Journal of Legal Medicine. - 2014. No. 128 (3). - P. 515-522.

7.AlQahtaniS.J. Accuracy of dental age estimation charts: Schour and Massler, Ubelaker and the London Atlas / S. J. AlQahtani, M. P. Hector, H. M. Liversidge // American Journal of Physical Anthropology. - 2014. - No. 154 (1). - P. 70-78.

8. Kostenko Y. Possibility of improving method of age determination during pathological attrition / Y. Kostenko, M. Goncharuk-Khomyn // The Journal of Forensic Odonto-stomatology. - 2013. - No. 31. - P. 67-68. 9. Age-and sex-related growth patterns of the craniofacial complex in European children aged 3-6 years / J. Tutkuviene, C. Cattaneo, Z. Obertová [et al.] // Annals of Human Biology. - 2016. - No. 43 (6). - P. 510-519.

10. Thevissen P. W. Human age estimation combining third molar and skeletal development / P. W. Thevissen, J. Kaur, G. Willems // International Journal of Legal Medicine. - 2012. - No. 126 (2). - P. 285-292.

11. AlQahtani S. J. Accuracy of dental age estimation charts: Schour and Massler, Ubelaker and the London Atlas / S. J. AlQahtani, M. P. Hector, H. M. Liversidge // American Journal of Physical Anthropology. - 2014. No. 154 (1). - P. 70-78.

12. Blenkin M. Age estimation charts for a modern Australian population / M. Blenkin, J. Taylor // Forensic значення віку за стоматологічним статусом у різних вікових групах при різних методологічних підходах, що, у свою чергу, дозволить спростити алгоритм судово-стоматологічної оцінки зубощелепного апарату в ході проведення комплексних судово-медичних експертних та слідчих заходів.

Science International. - 2012. - No. 221 (1). - P. 106-112. 13. Forensic age estimation in living individuals: methodological consideration in the context of medicolegal practice / D. Franklin, A. Flavel, J. Noble [et al.] // Res. Rep. Forensic Med. Sci. - 2015. - No. 5. - P. 53-66.

14. Phillips V. M. Testing standard methods of dental age estimation by Moorrees, Fanning and Hunt and Demirjian, Goldstein and Tanner on three South African children samples / V. M. Phillips, T. J. van Wyk Kotze // J. Forensic. Odontostomatol. - 2009. - No. 27 (2). - P. 20-28. 15. Ethics in age estimation of unaccompanied minors / P. Thevissen, S. I. Kvaal, K. Dierickx, G. Willems // Journal of Forensic Odonto-Stomatology. - 2012. - No. 30 (1). P. 85-102.

16. Liversidge H. M. Bias and accuracy of age estimation using developing teeth in 946 children / H. M. Liversidge, B. H. Smith, M. Maber // American Journal of Physical Anthropology. - 2010. - No. 143 (4). - P. 545-554.

17. Accuracy of three age estimation methods in children by measurements of developing teeth and carpals and epiphyses of the ulna and radius / R. Cameriere, S. De Luca, R. Biagi [et al.] // Journal of Forensic Sciences. 2012. - No. 57 (5). - P. 1263-1270.

18. A comparison of Demirjian's four dental development methods for forensic age estimation in South Australian sub-adults / S. J. Flood, D. Franklin, B. A. Turlach, J. McGeachie // Journal of Forensic and Legal Medicine. - 2013. - No. 20 (7). - P. 875-883.

19. Applicability of the Demirjian method for dental age estimation in western Turkish children / M. Altunsoy, B. G. Nur, O. Akkemik [et al.] // Acta Odontologica Scandinavica. - 2015. - No. 73 (2). - P. 121-125.

20. Cruz-Landeira A. Dental age estimation in Spanish and Venezuelan children. Comparison of Demirjian and Chaillet's scores / A. Cruz-Landeira, J. Linares-Argote, M. Martínez-Rodríguez [et al.] //International Journal of Legal Medicine. - 2010. - No. 124 (2). - P. 105-112.

21. Rai B. Dental Age Estimation / B. Rai, J. Kaur // Evidence-Based Forensic Dentistry. Springer Berlin Heidelberg. - 2013. - P. 35-63.

22. Blenkin M. R. Age estimation from the teeth using a modified Demirjian system / M. R. Blenkin, W. Evans // Journal of Forensic Sciences. - 2010. - No. 55 (6). P. 1504-1508.

23. Kırzıoğlu Z. Accuracy of different dental age estimation methods on Turkish children / Z. Kırzıoğlu, D. Ceyhan // Forensic Science International. - 2012. No. 216 (1). - P. 61-67. 


\section{References}

1. Franco, A., Thevissen, P., Coudyzer, W., Develter, W., Van de Voorde, W., Oyen, R., Willems, G. (2013). Feasibility and validation of virtual autopsy for dental identification using the Interpol dental codes. Journal of Forensic and Legal Medicine, 20 (4), 248-254.

2. Lin, P. L., Lai, Y. H., \& Huang, P. W. (2012). Dental biometrics: Human identification based on teeth and dental works in bitewing radiographs. Pattern Recognition, 45 (3), 934-946.

3. Berketa, J. W., James, H., \& Lake, A. W. (2012). Forensic odontology involvement in disaster victim identification. Forensic Science, Medicine, and Pathology, 8 (2), 148-156.

4. Pittayapat, P., Jacobs, R., De Valck, E., Vandermeulen, D., \& Willems, G. (2012). Forensic odontology in the disaster victim identification process. J. Forensic Odontostomatol., 30 (1), 1-12.

5. Stavrianos, C., Georgaka, E., Sarafidis, G., Aroni, D., Vasiliadis, L., Tretiakov, G., \& Petalotis, N. (2012). Dental and oral features useful in identification. Research Journal of Medical Sciences, 6 (2), 33-41.

6. Focardi, M., Pinchi, V., De Luca, F., \& Norelli, G. A. (2014). Age estimation for forensic purposes in Italy: ethical issues. International Journal of Legal Medicine, 128 (3), 515-522.

7. AlQahtani, S.J., Hector, M.P., \& Liversidge, H.M. (2014). Accuracy of dental age estimation charts: Schour and Massler, Ubelaker and the London Atlas. American Journal of Physical Anthropology, 154 (1), 70-78.

8. Kostenko, Y., \& Goncharuk-Khomyn, M. (2013). Possibility of improving method of age determination during pathological attrition. The Journal of Forensic Odonto-stomatology, 31, 67-68.

9. Tutkuviene, J., Cattaneo, C., Obertová, Z., Ratnayake, M., Poppa, P., Barkus, A., ... \& Ritz-Timme, S. (2016). Age-and sex-related growth patterns of the craniofacial complex in European children aged 3-6 years. Annals of Human Biology, 43 (6), 510-519.

10. Thevissen, P. W., Kaur, J., \& Willems, G. (2012). Human age estimation combining third molar and skeletal development. International Journal of Legal Medicine, 126 (2), 285-292.

11. AlQahtani, S.J., Hector, M.P., \& Liversidge, H.M. (2014). Accuracy of dental age estimation charts: Schour and Massler, Ubelaker and the London Atlas. American Journal of Physical Anthropology, 154 (1), 70-78.

12. Blenkin, M., \& Taylor, J. (2012). Age estimation charts for a modern Australian population. Forensic Science International, 221 (1), 106-112.

13. Franklin, D., Flavel, A., Noble, J., Swift, L., \& Karkhanis, S. (2015). Forensic age estimation in living individuals: methodological consideration in the context of medicolegal practice. Res. Rep. Forensic Med. Sci., 5, 53-66.

14. Phillips, V.M., \& van Wyk Kotze, T.J. (2009). Testing standard methods of dental age estimation by Moorrees, Fanning and Hunt and Demirjian, Goldstein and Tanner on three South African children samples. J. Forensic Odontostomatol., 27 (2), 20-28.

15. Thevissen, P., Kvaal, S. I., Dierickx, K., \& Willems, G. (2012). Ethics in age estimation of unaccompanied minors. Journal of Forensic Odonto-Stomatology, 30 (1), 85-102.

16. Liversidge, H.M., Smith, B.H., \& Maber, M. (2010). Bias and accuracy of age estimation using developing teeth in 946 children. American Journal of Physical Anthropology, 143 (4), 545-554.

17. Cameriere, R., De Luca, S., Biagi, R., Cingolani, M., Farronato, G., \& Ferrante, L. (2012). Accuracy of three age estimation methods in children by measurements of developing teeth and carpals and epiphyses of the ulna and radius. Journal of Forensic Sciences, 57 (5), 1263-1270. 18. Flood, S. J., Franklin, D., Turlach, B. A., \& McGeachie, J. (2013). A comparison of Demirjian's four dental development methods for forensic age estimation in South Australian sub-adults. Journal of Forensic and Legal Medicine, 20 (7), 875-883.

19. Altunsoy, M., Nur, B.G., Akkemik, O., Ok, E., \& Evcil, M.S. (2015). Applicability of the Demirjian method for dental age estimation in western Turkish children. Acta Odontologica Scandinavica, 73 (2), 121-125.

20. Cruz-Landeira, A., Linares-Argote, J., MartínezRodríguez, M., Rodríguez-Calvo, M. S., Otero, X. L., \& Concheiro, L. (2010). Dental age estimation in Spanish and Venezuelan children. Comparison of Demirjian and Chaillet's scores. International Journal of Legal Medicine, 124 (2), 105-112.

21. Rai, B., \& Kaur, J. (2013). Dental age estimation. In evidence-based forensic dentistry. Springer Berlin Heidelberg, 35-63.

22. Blenkin, M. R., \& Evans, W. (2010). Age estimation from the teeth using a modified Demirjian system. Journal of Forensic Sciences, 55 (6), 1504-1508.

23. Kırzıoğlu, Z., \& Ceyhan, D. (2012). Accuracy of different dental age estimation methods on Turkish children. Forensic Science International, 216 (1), 61-67.

Отримано 17.09.17 